\title{
The experience of Ubuntu to a hospitality organisation: Scale development and validation
}

\author{
Thembisile Molose * \\ Cape Peninsula University of Technology, Cape Town, South Africa
}

\author{
Keywords \\ Culture \\ Organisational performance \\ Measurement scales \\ Ubuntu \\ South Africa
}

Received: 3 April 2019

Accepted: 7 May 2019

Published: 28 June 2019

\begin{abstract}
The objective of this paper was to identify what hospitality frontline managers experience as Ubuntu and subsequently presents a compact assessment scale for measuring frontline managers' experience of Ubuntu culture to a hospitality organisation in South Africa. A mixed-method research design encompassing qualitative and quantitative studies resulted in 26 item measures for the Ubuntu concept. The two studies were conducted to test aspects of a fourfold model of Ubuntu which integrates compassion (care, empathy, being there physically and emotionally), survival (ability to survive in spite of difficulties, a shared will to survive and focus), group solidarity/collectivism (the idea of achieving collectively; organisation exists to benefit employee community), and respect and dignity (valuing the worth of others). In Study 1, scales were developed to measure these aspects. Relationships among the four values of Ubuntu and with variables considered their antecedents were examined in Study 2. Results of a factor analysis suggested that, as predicted by the fourfold model, Ubuntu values are empirically distinguishable dimensions that can be experienced simultaneously by frontline managers. The importance of encouraging the study of Ubuntu as a culture, both in research and to the organisation, is discussed. The implication of this research is that, fostering Ubuntu's compassion and collectiveness as (a "gift that Southern Africa can give to the world)" could enable organisations to attract employees who feel authenticity from managers that align with their individual values, which then generate positive attitudes and work behaviours in employees. Therefore, South Africa's hospitality sector needs to foster stronger team relationships, through the authenticity of support by the supervisor and social activities. As such, the study suggested that the culture of Ubuntu, if consciously harnessed can play a pivotal role in managing diverse workforce.
\end{abstract}

\section{INTRODUCTION}

\section{Statement of the Research Problem}

Ubuntu in this study is accepted as defined by Khoza who defined it as "an African value system that means humanness, which is characterised by caring, sharing compassion, communocracy and related predispositions" (Khoza, 1994). Almost all definitions of Ubuntu found in the literature (Battle, 1996; Broodryk, 2005; Mangaliso, 2001) have three common denominations which are principally concerned with actions that are welcoming, accommodating, sharing and sustaining human relations and behaviour. Familiar connotations like Umu-ntu ngumu-ntu ngabantu, which means, "each individual's humanity is expressed in relations with others" (Battle, 1996; Naeem \& Hameed,
2018) or a person can only be a person through others (Mbigi, 1997; Mertz, 2007), are common among the Zulus and Xhosa people. The term Ntu (this person) translates to kindness, and African humanness (Qobo \& Nyathi, 2016). Most Zulu and Xhosa people in South Africa also use terms like 'Sawubona' when they greet which simply means, I see you (as a human) and 'Simunye' (meaning, we are one) as a show of Ubuntu. For Mbigi (2000), the literal meaning of Ubuntu is "I am because you are-I can only be a person through others". Tutu (2011) remarks that Ubuntu is the essence of being human, and an important part of the gift that Africa has to give to the world.

In view of the above, Ubuntu in this study is translated as:

- The African principles of Ubuntu (humanness) may not be

${ }^{*}$ corresponding author: Thembisile Molose

†email: moloset@cput.ac.za 
emphasised to the same extent in other contexts, such as Western countries (Broodryk, 2005; Khoza, 2004).

- Ubuntu captures the essence of what it means to be human. It is the sense of responsibility towards the other that makes Ubuntu resonate with African beliefs and cultural systems (Khoza, 1994; Yazici, 2016) and Broodryk (2005). - Ubuntu (African humanness) reflects humanity with a universal appeal of southern Africa traditional community values; (in most sections of southern Africa, the burdens of the community are shared such that no one is prejudiced) (Broodryk, 2005; Cuyugan et al., 2017; Khoza, 1994; Qobo \& Nyathi, 2016).

- In Ubuntu (African humanness), everything is done to put the interest of the community ahead of the interests of an individual. Its premise is based on selflessness and commitment of an individual to one's community more than individual achievement and therefore, the tendency seems quite different from the notion of humanness generally (Broodryk, 2005; Khoza, 1994; Mgidlana, 1997; Qobo \& Nyathi, 2016).

The above translations encapsulate the essence of the philosophy of Ubuntu. Nevertheless, the fundamental value of Ubuntu and how it manifests could present a narrow interest, at the same time it may go a long way in a complex society such as South Africa. Problems identified in the South African hotel industry appear to be centred on managers who do not have an understanding or knowledge of the various cultures and languages of the employees (Nicolaides, 2010). Studies show that there is a lack of genuine attempts by managers to hear or understand what the frontline employees have to say. The point being emphasised in this review mirrors on the strength of the behavioural expression of Ubuntu and group consensus, which provides employees within a service business context to air their views, because reaching group consensus about collective-work performance improvements may be central to Ubuntu.

The literature on African culture, and various management styles, suggest that Ubuntu has the potential to determine the levels of employees' commitment and work performance improvements by assessing who exhibits collectivist-cultural values. The National Tourism Service Excellence Strategy developed in 2011 by the National Department of Tourism (NDT) in collaboration with the National Department of Arts and Culture in South Africa identified Ubuntu as one of the building blocks that tourists as customers associate with in their consumpution of hospitality products and services (The National Department of Tourism, 2011). Conceptually, hospitality is premised on welcoming and serving strangers by hosts (Westmoreland,
2008) is typically featured in an Ubuntu hospitality context. In Africa, it is traditionally widely accepted that a host will open his/her home to total strangers, giving them a place to stay and a meal to eat although he/she knows little about them (Westmoreland, 2008). In the workplace, Ubuntu seems to be principlally concerned with supporting group solidarity in team work, and in turn, a collective achievement orientation by employees to attaining organisational goals. This led (Browning, 2006) to conclude that managers who behave in a way that contradicts the expectations of their employees do not realise the positive influence that Ubuntu can have on how employees interact with customers. Therefore, to benefit from the premise of Ubuntu philosophy requires that hospitality managers model the way of practising its principles for employees in return for their own experience of Ubuntu from them as superiors. Although Ubuntu seems is touted as a meaningful and alternative organisational approach, and collective achievement of organisational goals, empirical investigation on what Ubuntu means to an employee has so far been neglected in the hospitality literature.

Although there are numerous validated instruments to measure servant leadership (Brubaker, 2013), employee job satisfaction (Kiefer et al., 2005), human resources management practices (Browning, 2006; Eisenberger, Stinglhamber, Vandenberghe, Sucharski, \& Rhoades, 2002; Kim, Leong, \& Lee, 2005) service quality performance (Babakus, Yavas, Karatepe, \& Avci, 2003) in a hospitality context, there is still no well-developed instrument to measure Ubuntu experience by employees in a service environment such as hospitality. One of the relevant measurement scales of Ubuntu, that has particular relevance to this study, was developed by Sigger, Polak, and Pennink (2010) and tests a sample of managers in Tanzanian organisations. Even though the work of Sigger et al. (2010) in developing Ubuntu measurement scales should be acknowledged, it must be mentioned that some measures, particularly group solidarity, survival, and respect and dignity were not without limitations. The authors of these scales acknowledged that the low Cronbach's alpha scores (0.543 to 0.69 ) on the above mentioned dimensions were attributed to a) the number of measurement items (11 for each Ubuntu dimension), and b) lack of participants' understanding of the literal meaning of questions. These authors concluded that a relevant and useful measurement tool for operationalisation of Ubuntu practice in the workplace should be developed. 


\section{Aims and Research Questions}

The objective of this paper is to identify what hospitality frontline managers experience as Ubuntu and subsequently presents a compact assessment scale for measuring frontline managers' experience of Ubuntu culture to a hospitality organisation in South Africa. It asks the question, what do managers as employees experience when they encounter Ubuntu in the workplace, and what dimensions of Ubuntu can be distinguished? The specific aims were to:

1) explore the literature on Ubuntu to identify themes and antecedent conditions that can be used to describe Ubuntu experience.

2) develop a multi-measurement tool of the Ubuntu concept and, to enable the collection of empirical data of Ubuntu experience by employees (frontline-managers) to a hospitality organisation.

\section{Significance of the Study}

According to Mangaliso (2001), Ubuntu is a conventional African wisdom that supports those customs and practices that serve a common good. Ubuntu is founded on South Africa's Zulu-Xhosa aphorism, Umuntu-ngumuntu ngabantu, which means that 'each individual's humanity is expressed in relation with others' (Battle, 1996). Mbigi (1993) regards Ubuntu as the essence of the South African corporate renewal and a useful way in which to marry African, Western and Eastern ideology in order to achieve world-class status. In support of African and International writers of Ubuntu, Tutu (2011) gives credence to Ubuntu by pointing out that it is one unique concept that Africa can offer to the world. Essentially, Ubuntu is a major part of African management that introduces a humanistic view on people as opposed to western approaches which view people as another tool to meet the objectives of the instrumental organisation (Jackson, 2004). However, it should be noted that South Africa is a complex society made up of several contexts evidenced by divergent views, ideas, and cultural values and therefore, Ubuntu cannot be popularised as an attempt to replace existing management practices or redress previous imbalances. The basic values of Ubuntu, which could manifest itself in the ways South African people think and behave towards each other and everyone else they encounter, should be promoted. It is against this background that, the contribution that recognises the value of Ubuntu to service management knowledge is through its extension of measurement and well established theories of individualism-collectivism dimensions (Hofstede, 1980; House, Hanges, Javidan, Dorfman, \& Gupta, 2004) for directing high performance teams in the workplace.

\section{Scope and Context of the Study}

This research adopted both qualitative and quantitative methods conducted in a sequential manner. This sequential methodology combination provided triangulations between both research methods applied and, types of data collected, which lent itself to the reliability of the data collected. The study was conducted in three-, four- and fivestar graded tourist hotels in South Africa. The tourist hotel accommodation sub-sector in South Africa consists of multi-national and multi-international hotel brands as well as privately owned hotels. The chosen hotels were identified through several sources, namely, (a) Tourism Grading Council of South Africa (TGCSA), (b) CATHSSETA, (c) TripAdvisor, and (d) South African Tourism Lilizela awards. The hotel industry has a series of characteristics that are very suitable for this study. First, the hotel service industry provided a unique environmental context in terms of diversity related to size, star rating, number and type of employees, scope and scale of functions, and fiscal positions (Petzer \& Steyn, 2006). The South African owned hotel groups of companies which were chosen for this study were considered likely to have frontline managers aware of the Ubuntu culture.

For the sampling method, the researcher of this stdy chose the convenience sampling method. Previous hospitality research (Brubaker, 2013; Strauss et al., 2016) used convenience samples because of the difficulty in obtaining permission from employees identified through random sampling techniques, so convenience sampling allows every employee approached, and who agrees to participate, an opportunity to participate. A convenience sample of 336 frontline-managers in 56 tourist hotels, covering nine provinces in South Africa was surveyed using a structured questionnaire.

\section{LITERATURE REVIEW \\ Collective-Finger's Theory of Ubuntu}

The articulation of togetherness and communism in an Ubuntu practicing community can be found in Mbigi and Maree (1995) who developed a conceptual framework known as the collective fingers theory. As illustrated in Figure 1 , the theory organised the five key principles/social values of Ubuntu widely known as survival, compassion, the spirit of solidarity, respect, and dignity in a conceptual framework that describes its antecedents.

According to Mbigi and Maree (1995) the principle behind the fingers theory can best be explained by the African proverb, "a thumb, although it is strong, cannot kill on its own. It requires the collective co-operation of the other fin- 
gers" to do this. The African proverb according to Mbigi and Maree (1995) can be seen in two ways: First, the fingers should be seen as individual persons who act together in a collective manner in order to achieve a certain goal. Second, the fingers represent key values that are necessary to form and maintain a collective culture. Mbigi (1997) complemented the collective fingers theory pointing out that these values have always been part of the African culture. It can be seen that Mbigi and Maree (1995) theory was organised into a model of Ubuntu through collective fingers. Thus, from the discussion that has preceded the established broad collective-values of Ubuntu a theoretical framework is proposed that integrates a global view as it stands at this point into a fourfold model. The proposed framework has received support from empirical research discussed in the follow-up section. Figure 1 therefore, proposes the collective-values framework of Ubuntu to guide managers in developing leadership characteristics appropriate to supervising a collective team in a South African workplace.

The overall impression of Ubuntu theory presented in Figure 1 suggests that the concept can be seen as one of the mechanisms capable of promoting synergy and the creation of a whole that is larger than the sum of the individual parts, which is seen it as an integral part of Africa culture
(Mangaliso, 2001). This could be made possible when people show compassion, love, and respect for one another; Tutu (2011) encouraged that Ubuntu requires common understanding between the supervisor and team members that they are able to help and care for each other as members of one family or organisation. Jackson (2004) remarks that Ubuntu's point of departure should be centred on the leaders as a cohesive force within the group because every aspect of being human should define their role as one of a team. There is research propounded by MacDonald, Kelly, and Christen (2019), which support the view that supervisors must put forth more effort than their subordinates must to build solidarity. Importantly, team solidarity and commitment are said to be a function of strong relationships with others, teamwork, and strong loyalty to group goals. One theory that emerged recently in the field of African management is Ubuntu-relational holder theory (Woermann \& Engelbrecht, 2019), according to which, collective decision-making fosters and explains Ubuntu for management, with reference to the aphorism 'a person is a person through others'. Explaining collective decision making as an integral part of Ubuntu values may imply that managers can only be successful managers because of their teams.

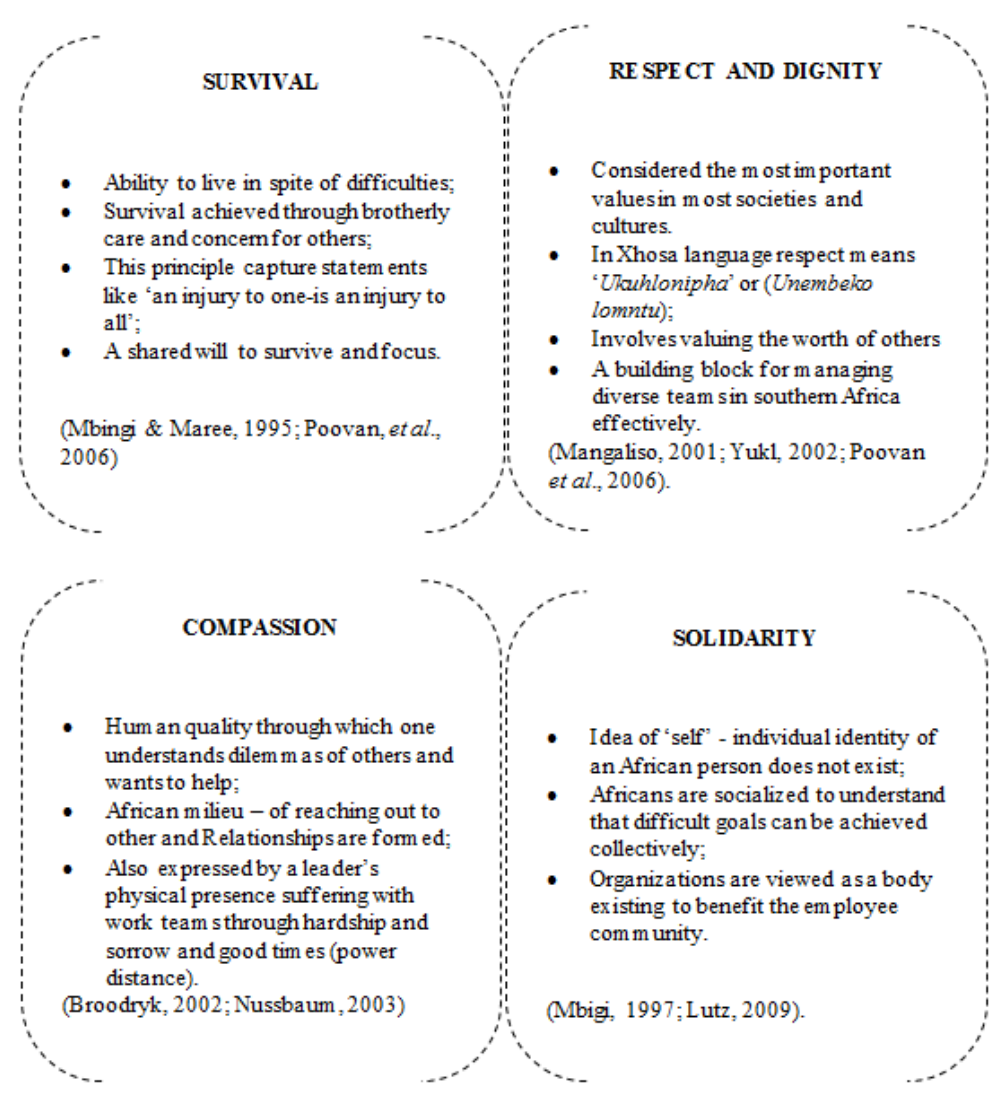

FIGURE 1. The Fourfold Model of Ubuntu's collective values (Source: Adapted from Molose, Thomas, and Goldman (2019)) 


\section{RESEARCH METHODOLOGY}

\section{Phase 1: Exploring the Concept, Content Validity and Item Generation}

The development of the experience of Ubuntu by frontlinemanagers entailed both, an explorative and confirmative phase, consisting of three studies. The objective of phase one in the development of Ubuntu scale was to define the concept and to generate items. This phase consisted of two qualitative studies, the first explored the meaning of Ubuntu from the viewpoints of frontline-managers and academics involved in Ubuntu-hospitality practising environments and the second study explored it from the viewpoints of knowledgeable persons about Ubuntu. Phase two, stage 3 includes the purification of the scale and the validation of the factor structure.

\section{Study 1: Qualitative Interviews}

Initially, the collection of data entailed interviewing 25 purposively selected (15 hospitality frontline-mangers and 10 hospitality academic lecturers and instructors) as research participants, and analysing this data in stage one.

\section{Method}

- A convenience sample of 15 frontline managers from two hotel groups, with a total of seven hotels: three three-star, three four-star and one five-star graded tourist hotels

- A purposive selection of 10 hospitality academics from four universities in South Africa.

Initiating permission for interviews and the survey to be done at the hotel chain required that contact be first made with the head office of the hotel group. Upon obtaining permission from head office, invitation letters were sent via email to general managers, and group operations directors. For both tourist hotels and academic hospitality departments, the invitation letter for participation in the study described the goal of the research and requested one-on-one interviews for qualitative data using an interview schedule. Access to knowledgeable individuals with the following characteristics was requested:

- Willingness to participate and contribute voluntarily to the study

- Working in a South African tourist hotel or a university offering hospitality management programmes

- Ability to speak any one of the indigenous African-Nguni languages and/or knowledgeable about the concept of Ubuntu

- Employed for more than 12 months in the South African tourist hotel industry or university offering hospitality management qualification, to ensure intimate knowledge of customer service in the South African hospitality industry. Purposeful selection of participants with the required experience allowed intricate insights and diverse views into the phenomenon and ensured an answer to the research question.

\section{Research Design}

Prior to commencing the face-to-face interviews, telephone calls were made to each of the 25 participants and the goals of the field research were explained (see Table 1). In this process, participants were once again given assurance that: - Participation in the study was completely voluntary

- All interviews would be treated confidentially and the recordings would not be included in the outcome of the study

- Total anonymity was guaranteed; no names, reference to them and their organisation, or anything that could incriminate them would appear in any publications forthcoming from the study

- Instead of using a name of the participants or organisation, direct quotations would be either under a pseudonym, for example, a hotel would be coded as H1, university as U1, and I 1 or I 2 would stand for interviewees, depending on the context.

The interviews took place from August to October 2017 each lasting between 30 and to 90 minutes, on average 45 minutes. Interviews took place mostly at the location choice of the participants, where they felt comfortable to express themselves. With the permission of the research participants, a digital recorder (voice tracker) was used to record all 25 interviews, and transcribed verbatim into Mi-

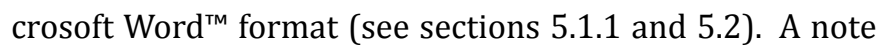
pad was kept throughout the interviewing process resulting in the field notes and memos used for complementing the recorded interviews. These field notes were included in the transcripts as points of clarity when needed. The order of the topics and probing varied according to the participant's responses to the questions, which helped determined the flow of the interview discussions thus, following up on areas that needed clarity. The researcher commenced with the interviews by opening with a familiar topic, asking for work background and the experience of the participant with the organisation/institution. This strategy helped to alleviate any anxiety that the participants might have felt prior to introducing the more sensitive topics. The interview then progressed using the interview guide as a loose framework (Brod, Tesler, \& Christensen, 2009).

Interviews took place mostly during normal working hours (08:00 to 17:00), in quiet and convenient locations in par- 
ticipants working environment where they felt comfortable to express themselves. Furthermore, all interviews were conducted simultaneously. This process helped assess how the research participants differed in their understanding of Ubuntu, the influence on management of frontline employees, and service quality training. Like frontline managers, hospitality academics are involved in the training and researching of frontline employees' developmental attributes and the required attitudes in service delivery situations. Therefore, soliciting insights from hospitality academics was as important as obtaining insights from frontline managers on this topic.

Based on the above, each interview was treated as unique as possible giving each participant the opportunity to talk freely about his or her experience and encouraging them to provide examples of incidents and events that might be of importance to the discussion. If the research participant said he/she was unhappy with how they were treated by managers or the organisation/institution, then the researcher would probe asking if participants could remember a recent incident with regard to that specific treatment that made him/her unhappy. Overall, flexibility was considered the most important factor as interaction with participants was only to guide the discussion topics thereby allowing them to do most of the talking.

During the interviewing discussion, questions like 'how would you expect your manager to see him/herself as part of a team', and 'how would a stranger be shown Ubuntu in their workplace' were explored. In responding, participants were requested to tell a story or relate responses to a previous situation that represented their responses to these questions. In this sense, the story telling was incorporated to explore the practical meaning and elements that make Ubuntu. Storytelling involves events and characters, what the characters say and do, and signifies the way the story is told as the mode established by Khoza (1994). Storytelling in this research coincided with the recommendations in the literature suggesting that the generation of African knowledge, particularly, that of culture should be developed through African ways (Nussbaum, 2003; NewenhamKahindi, 2009). Ultimately, some stories of Ubuntu reconnecting with previous research emerged during the data analysis showing new patterns and trends of Ubuntu that may help practitioners to rethink management of organisations operating in Southern Africa where the majority of people represent Nguni speaking ethnic groups.

\section{Data Analysis}

The first step in the analysis process was loading Atlas/ti (statistical software), version 8 (Archer, Herman, van Vuuren, \& Hugo, 2017). After listening to the voice recorded interviews, reflecting on their content, each individual interview was transcribed into a Microsoft Word ${ }^{\mathrm{TM}}$ document and imported into Atlas/ti (Swanson \& Holton, 2005). The second task was reading and re-reading the transcripts, jotting down impressions of what the transcripts inferred against the background of literature reviewed (Basit, 2003; Swanson \& Holton, 2005). The deeper and richer the understanding of the interview transcripts became, the more ideas and patterns (based on what was seen in the data at thematic level) emerged from the data.

As the process unfolded, time away from the data was spent writing and reflecting on the list of categories that kept emerging in an attempt to understand the intricacies of the data (Swanson \& Holton, 2005). Each chunk of data was labelled with a descriptive code and compared with each new chunk so that similar chunks of data could be labelled with same code. Once all data was coded, the codes were then grouped by similarity, thereby helping to identify the themes. The outcome was the development of a long list of preliminary codes in a Microsoft Excel ${ }^{\mathrm{TM}}$ spreadsheet as the beginning of the process of developing themes through template analysis. The researcher was aware that influencing the data analysis process in any way should be avoided. Any speculations were kept to a minimum (Swanson \& Holton, 2005). To minimise bias, and improve inter-rater reliability, two procedures were performed. The first included making the results available to the research participant and then asking them to provide input on whether the data accurately reflected their experiences. Secondly, the researcher invited two professional colleagues, who were familiar with the goals of this research and had worked in hospitality environments, to act as peers. These colleagues independently reviewed the content analysis and interview transcripts to see if they agreed with the categories of themes and concepts derived. These precedures resulted in minor changes to the original coding scheme.

The views, experiences, and patterns of Ubuntu domains, as they emerged from the qualitative statements of the research participants, were analysed by following the approaches recommended by Corbin and Strauss (1990):

- Step 1-Opening coding: This process entailed careful inspection of the data with the goal of breaking it into useful meaningful units (Corbin \& Strauss, 1990; Onwuegbuzie, Dickinson, Leech, \& Zoran, 2009). In this process, conceptual labels were developed from the units of data represent- 
ing events, actions, interactions, and emotions, which were then compared for similarities and differences (Brod et al., 2009; Corbin \& Strauss, 1990). In turn, these labels were grouped together into categories and sub-categories. Keeping this in mind, each of the labelled codes was re-evaluated in order to flesh out the dimensions and properties of the category. This suggested that each of these categories had a property of type, which was further broken down into subtypes (Corbin \& Strauss, 1990). In this instance, some actions or comments from the participants were noted and labelled, for example: "Communism" under Ubuntu phenomena and then labelled the subtype as "sharing with others or my child is your child". Once the above categories and their properties were identified, the next observation entailed looking closely at instances of each and taking note of different kinds and what types and so forth.

- Step 2-Axial coding: The categories developed in step one were connected to their sub-categories and assumed to be tested against the data (Brod et al., 2009; Corbin \& Strauss, 1990). These connections between the categories were made by ensuring that each represented the concepts under study. Further development of categories took place by looking for indications of them in the data. During the analysis, context in terms of which emerging category is carried out was scrutinised to determine the conditions that gave rise to the category through which it occurs.

- Step 3-Selective coding: In selective coding, all categories are unified around a core category, which represents the central phenomenon of the study (Corbin \& Strauss, 1990). The step involved conceptualising the findings in a few sentences, explaining the essence of the events or interactions, and explaining the variation between and among the categories. In this sense, one or more themes that express the content of each of the groups of categories can be developed as the essence of what is investigated (Brod et al., 2009; Corbin \& Strauss, 1990; Onwuegbuzie et al., 2009). Upon grouping all the categories that emerged during open and axial coding, studying all 25 transcripts and summaries repeatedly, and links were found between 47 categories. These were consolidated to result in 22 categories. At this point, a network relationship was produced to make sense of the links between the categories (Basit, 2003). Once again, the transcripts were perused before requesting two independent reviewers for comments and input into the data networks. Illuminative quotations from the transcripts were highlighted and studied against the 22 identified categories. Arising from this, the categories were found to be connected with one another and were grouped according to similarities and differences, which captured both negative and positive elements that were condensed culminating in two core themes:

(1) Societal changes-Letting go of old-ways: Research participants tended to reflect on distinctive dimensions during the interviews. They reflected on the relationship between managers and subordinates, because they need each other, the success of managers depends on people working for them, and not getting views of employees on how to improve work. Furthermore, separation as a move from unity, where managers tend to create space and distance themselves from teams, to individualism, allowing the team to attend to cultural activities and making arrangements without deducting from their salary. Some participants indicated that Ubuntu is sometimes perceived as a culture associated with African people. These reflections indicated that different people associate views on organisational practices based on their experiences, where they are in their career in the organisation, and to what views they are accustomed. Belongingness - I am because you are: The research participants were very unapologetic about managers who were distancing themselves from junior managers and staff alike. They tended to emphasise their expectation that top management have to be team players, must be close to staff; thus, being there physically and emotionally. These reflections were consistent with slogans identified in the literature like Umuntu ngumu-ntu ngabantu. Although this 'united front' view does not necessarily mean that each research participant promoted the supremacy of Ubuntu, they knew full well that creating and maintaining unity and social relationships is a process that is complex (due to different cultural backgrounds), multi-faceted, and taxing. Therefore, for the findings to be meaningful in the context of the South African organisation, an understanding of these perspectives is crucial, as this contextualises perceptions of and feelings towards their experiences of Ubuntu in practice. The overall picture presented by this qualitative research portrayed Ubuntu as a Southern African heritage that promised belongingness, togetherness, and communocracy. Thus Ubuntu is also seen as an ethnic culture with a stigma that suggests practising an ancient wisdom in a modern society may not be the same, as put by (Esterberg, 2002).

\section{FINDINGS}

Evidence from the interviews showed that participants tended to reflect on distinctive elements representing Ubuntu. For instance, the two categories highlighted above represents the accounts of participant's reflection on manager-subordinate relationship (expressing that both need each other), and emphasise that the success of a man- 
ager depends on people working for him/her. Others reflected on negative issues such as managers not obtaining the views of employees on how to improve work or separation of unity-whereby managers tend to create a space or gap between them and the employees, thus, distancing themselves from work teams (individualism). Some participants indicated that Ubuntu is sometimes perceived as culture associated with African people and letting go of old ways of thinking. These reflections indicated that different people associate views on organisational practices based on one's experiences and from what they are accustomed to. Furthermore, in terms of belongingness, the participants were very unapologetic about managers who were distancing themselves from junior managers and staff alike. They emphasize their expectation that top management have to be team players, must be close to staff, thus, being there physically and emotionally. These reflections were consistent with slogans identified in the literature like 'Umuntu ngumu-ntu ngabantu'. Although this "belongingness" view does not necessarily mean that each participant was promoting the supremacy of Ubuntu, each of them was consciously aware that creating and maintaining unity and social relationships is a process that is complex and could be impeded by different cultural backgrounds. In this sense, understanding of these perspectives is crucial, as this contextualises perceptions and feelings of people on the ground towards their experiences of Ubuntu in the organisation. From these findings, supplemented by extant literature, the researcher developed what he believed would be multidimensional scale of Ubuntu for examination of Ubuntu management application in South African organisations.

\section{Delphi Study}

A Delphi study technique can be viewed as a "method for consensus-building" among a group of experts or knowledgeable participants (Van Dun, Hicks, \& Wilderom, 2017). Delphi techniques have been used because of its ability to assist researchers to arrive at effective decisions in situations that present contradictory or insufficient information in scale development (Hasson, Keeney, \& McKenna, 2000). Therefore, the Delphi survey method was implemented in this study for the following reasons, a) the scarcity of Ubuntu measurement scales focusing on style of management in hospitality organisations specifically in the literature, b) to test the trustworthiness of existing and new developed Ubuntu item measures.

\section{Method Participants}

Eight knowledgeable participants including academic scholars, writers on Ubuntu, and tourist hotel frontline managers were invited. Purposefully selecting the participants to be involved in the Delphi study was based on their experience and theoretical knowledge of Ubuntu. The decision for a sample size of eight participants in the Delphi study was a practical consideration, taking into account factors such as time available, number of rounds, and homogeneity of the sample. Five participants were fluent in Southern Africa Nguni languages (for example, Zulu, Xhosa, Ndebele) through their upbringing and associated culture. This was important in understanding the concept of Ubuntu, as Ubuntu forms part of the Nguni culture. The remaining three participants had a good theoretical knowledge of Ubuntu. Together, the Delphi study participants included six males and two females. Three of them were Xhosa speaking, two Ndebele speaking, one Zulu speaking, and two English speaking, thereby mitigating the issue of bias, and eliciting a wider knowledge base.

\section{Research Design}

A Delphi method was used: An interactive method in which experts (knowledgeable people) "discuss" a common problem (Jones \& Hunter, 1995). Through a structured iterative process the participants were requested to complete an online survey-over three rounds which entailed Ubuntu measurement items generated from the literature and exploratory interviews. The process included both, openended, allowing participants to provide input, and closedended questions on the most important Ubuntu values and behaviours. Specifically, the closed-ended survey questions listed the key values/constructs of Ubuntu and their antecedents generated from the literature and exploratory interviews conducted in phase one.

\section{Procedure}

Part of round one was to determine opinions by encouraging the participants to donate as many opinions as possible to maximise the chance of covering the most important opinions and issues regarding Ubuntu's practical behaviours. During this round, the questionnaire included closed-ended questions including 16 item measures, representing the four Ubuntu dimesnions. Participants were also requested to judge items in terms of quality and length, and their ability to capture the constructs of Ubuntu in practice. The intent was to assess the extent of agreement (consensus measurement) among the participants, and to resolve disagreement (consensus development) in subsequent rounds 
(Jones \& Hunter, 1995). In each round, participants were asked to spend 15 minutes of their time completing the questionnaire, and return it to the researcher within three days. In the second round participants were requested to score agreements (keep their initial score) with each statement or re-rate the scores based on the new additional 10 items in the questionnaire $(1=$ total disagreement and $5=$ total agreement). In the third round, the participants deliberated on a number of items, quality and length to reach consensus. Overall, participants provided input and opinions on the final pool of 26 Ubuntu item measures which were used in the final administration of the survey instrument that in stage three.

The steps followed for the Ubuntu scale development conformed to literature recommendations (Churchill Jr, 1979; Hinkin, 1995). Some of these items were modified versions of existing compassion dimensions in literature with measurement scales already used in other studies (Sigger et al., 2010; Strauss et al., 2016). As a result, through the combination of reviewing the literature and exploratory interview findings, 26 items measuring Ubuntu were identified for final inclusion in stage three of the survey. In the final round, the degree of consensus among the participants was assessed as very similar, after which the 10 new items were included. Thus, the process stopped and the results were fed back to the participants, as it was felt the degree of acceptable consensus building had been obtained (Jones \& Hunter, 1995). Upon revising and rewording all items, an attempt to select both positively and negatively worded items was made. Finally, 26 measurement items representing each Ubuntu construct was set at four each for survival and respect and dignity, and six each for compassion, group solidarity, and collectivism respectively.

\section{Analysis}

The scores of the responses provided in all three rounds were captured on Microsoft ExcelTM and averages of these scores were used to determine whether the participants agreed or disagreed with each other. Responses were summarised between rounds and fed back to the participants through a process of controlled feedback, which was repeated until consensus was reached. In this sense, the researcher kept informing the participants of the other participant's perspectives, and provided the opportunity for the participants to clarify or change their views, without influencing them. The aggregation of participant's scores (averages), after evaluating Ubuntu measurement items, enabled the quantitative analysis and interpretation of the Delphi data, thereby knowing when to stop collecting views from participants.

\section{RESULTS}

In summarising the three iterative rounds, the response rate, which influenced the strength of support for the newly generated Ubuntu scale, conformed to the recommendations in the literature (Hasson et al., 2000; Jones \& Hunter, 1995). Of those five Ubuntu elements, the highest ranked mean scores were: respect and dignity (3.66), group solidarity (3.69), and survival (3.72) for round 1. Subsequently, Delphi round two was administered, and the participants scored the measurement items for each Ubuntu element achieving mean scores ranging from 4.75 to 5.5. During this process, 10 new measurement items, which the participants felt were important representations of Ubuntu, were included in round three. As a result, consensus agreement with these new measures was assessed. In round three, the mean score of 4.1 for collectivism, ranked the highest. The other measures: compassion, survival, group solidarity, and respect and dignity ranged from 3.4 to 3.7. In accordance with recommendations in the literature (Hasson et al., 2000) it can be said that the indicator of group consensus which is between 51 per cent to 80 per cent was achieved in this study.

\section{Phase 2: Quantitative Study and Validation}

This phase builds on these preceding studies by empirical testing of the research tool. It sought to cross-validate and refine the elements of the Ubuntu concept measures developed in stages one and two, and then cross-validate the questionnaire (see Appendix 1).

\section{Sample and Data Collection}

The survey was distributed to frontline managers as employees from 56 tourist hotels located across the nine provinces of South Africa. The questionnaire was administered over a 10-week period in 2018 (end of May to beginning of July). To enhance the response rate, support for frontline managers completing the survey was obtained from their respective general managers at each of the 56 tourist hotels. The endorsement of this research by these general managers helped enhance the interest and the importance of the research among the participants.

A total of 336 questionnaires were distributed and 212 were returned resulting in a response rate of 63 per cent. Hair et al. (2006) recommended a minimum sample size of 50 or larger for studies utilising Exploratory Factor Analysis (EFA) and a minimum of 200, or ratio of 10:1 for Confirmatory Factor Analysis (CFA). Therefore, this study's sample size was large enough to perform the statistical analyses 
employed.

\section{Data Analysis}

The data were analysed in several ways. A statistical Package for Social Sciences (SPSS, Version 25) was used for statistical analysis (IBM Corporation, 2013). Descriptive statistics including mean, standard deviation, and variance were computed for each of the 26 measures of Ubuntu scale items used in the study.The main data analysis techniques used were factor analysis and Structural Equation Modelling (SEM), as these were the most appropriate data analysis techniques for this type of research. Factor analysis was also used for testing.

\section{Validity and Reliability}

In terms of assessing validity, most of the constructs were developed from well-established literature and therefore, the adapted versions of various scales could be considered to possess content validity. Additionally, EFA was used with SEM to assess convergent and discriminate validity of the measures. As a result, the measurement models fit the data satisfactorily. Again, most of the factors loaded significantly ( $p=0.001$ ), indicating uni-dimensionality of the measures. Hair et al. (2006) procedures were followed to estimate the relative amount of convergent validity of the multiple item construct. The literature recommends 0.30 or 0.40 as the criteria for item retention Hair et al. (2006). Items were retained if they did not cross-load on to other factors, particularly where the factor was deemed important to the content of the construct domain and, only factors with an eigenvalue greater than one were retained so that a good or very good rotated structure is reflected. Convergent validity on the other hand is established if the average variance explained for each item accounts for 0.50 or more of the total variance (Hair et al., 2006). The average variance extracted for the Ubuntu dimensions was 0.54 .

Reliability is defined by (Hair et al., 2006) as an assessment of "the degree to which the observed variable measures the true value and is error free", thus, the opposite of measurement error. The most commonly used measure of reliability, which applies to the consistency among the variables in a summated scale, is internal consistency.The internal consistencies of the 17 summated items used in this research's instrument had satisfactory levels ( 0.73 to 0.88 ). To this end, the satisfactory levels achieved in this study showed that the developed instrument used was reliable, given that it is above the expected minimum recommended level of 0.70 (Churchill Jr, 1979; Hair et al., 2006). Taking these rigorous tests into account, which also included a Delphi survey technique, the results provided an indication that the measures in this study possessed adequate reliability and validity.

\section{Demographic Profile of Respondents}

Table 1 indicates the profile of the participants. Two hundred and twelve (212) usable questionnaires were returned, yielding a 63\% response rate. Respondents were 62 per cent female and on average 36 years old. The majority of the 212 frontline managers who participated had either a post-matric (hospitality certification) or a national diploma (60.7\%) and over 21 per cent had completed a grade 12 or national senior certificate. Just over fifty per cent (50.7) of the total sample were black South African frontline managers, followed by 29.2 per cent white.

TABLE 1. Demographic characteristics of the respondents $(N=212)$

\begin{tabular}{lll}
\hline \hline Characteristics & Frequencies & Percentage of Respondents \\
\hline Gender: Female & 130 & 61.6 \\
Male & 81 & 38.4 \\
Total & 211 & 100 \\
Education: Grade 11 or lower & 20 & 9.5 \\
Grade 12 (Matric) & 45 & 21.3 \\
Post-Matric Diploma or certificate & 128 & 60.7 \\
Baccalaureate degree & 14 & 6.6 \\
Post-graduate degree & 4 & 1.9 \\
Total & 211 & 100 \\
Marital status: Single & 107 & 50.7 \\
Married with no children & 14 & 6.6 \\
Married with children & 67 & 31.8 \\
Divorced & 9 & 4.3 \\
Widow/Widower & 4 & 1.9 \\
\hline \hline
\end{tabular}


TABLE 1. Continue...

\begin{tabular}{lll}
\hline Characteristics & Frequencies & Percentage of Respondents \\
\hline Living together/Cohabitant & 10 & 4.7 \\
Total & 211 & 100 \\
Job profile: Frontline-supervisor (or coordinator) & 78 & 36.8 \\
Frontline-Assistant manager & 46 & 21.7 \\
Frontline-manager & 88 & 41.5 \\
Total & 212 & 100 \\
Length of previous experience in the hotel industry: & & \\
Less than a year (12 months) & 4 & 1.9 \\
1-2 years & 18 & 8.5 \\
$2-5$ years & 35 & 16.6 \\
5 -10 years & 56 & 26.5 \\
$10-15$ years & 40 & 19 \\
$15-20$ years & 30 & 14.2 \\
More than 20 years & 28 & 13.3 \\
Total & 211 & 100 \\
\hline \hline
\end{tabular}

\section{Ubuntu Measures}

The Ubuntu concept was measured using a 26 -item questionnaire asking the participant to respond on a five-point response scale $(1=$ total disagreement and $5=$ total agreement). Of the 26 measures, 16 were the modified items adapted from Brubaker (2013), Sigger et al. (2010), and Strauss et al. (2016) 10 were compiled especially for this study. Ubuntu values were measured in this study using items, for example, "my manager is usually present (emotionally) to share my pain during difficult times", "I feel that my manager treats me with utmost respect and dignity", "I do helpful things that will benefit me and the colleagues I know", and "the well-being of my co-workers is important to me". In a study of Ubuntu management style in Tanzania (Sigger et al., 2010), and servant leadership in Rwanda (Brubaker, 2013), reliability coefficients of 0.82 and 0.87 respectively were reported. In this study, the alpha coefficient of the whole Ubuntu scale was 0.93 .

\section{Results}

Two scales were developed from the compassion scale (Strauss et al., 2016) and two items for the survival scale dimension (Sigger et al., 2010). Three scales (solidarity, respect and dignity, and collectivism), represented by 10 items, were developed through the process of designing the questionnaire from the qualitative study findings, and verified by the Delphi consensus feedback. To some extent, the respondents rated most of the dimensions of Ubuntu favourably. The Ubuntu scale indicated that the items, 'I see myself as part of a diverse work team', 'the well-being for my co-workers' and 'my manager expects me to respect his decision', were rated highest $(4.16,4.25$ and 4.37 respec- tively). For the first statement, this could indicate that frontline managers did not only work in direct contact with customers but also with each other, and therefore suggested that co-operation and being part of a team was as important as serving the customer.

The fact that respondents rated managers' expectations for respecting their decision the highest (4.25), could signal that either they showed genuine respect, or it could be an indication that managers did as they expected others to do to them. For example, when asked about whether the manager treated individual staff members as if they were a member of a family, the respondents rated this element favourably, with the mean score being 3.87. This statement reflected that respondents tended to view their managers as a part of the team. In this sense, the rating of this Ubuntu scale seemed more balanced.

The respondents rated more favourably statements such as 'my manager greets me whenever he/she sees me', 'shares his/her burden during hard times' $(3.32,3.34)$. Other statements such as 'my manager is usually available (physically) to suffer with me during difficult time' (3.39), 'sharing my difficulty with colleagues makes me strong', with a mean score of 3.49, highlighted the importance of sharing with others. Other statements which rated highly included contribution to work goals, (4.03), doing helpful things and sticking together as family (4.10).

More broadly, frontline managers of South African tourist hotel accommodation tended to believe that they could handle and solve work problems collectively by sacrificing and backing each other up, which then helped them solve customer-service related problems, as reflected by mean scores of between 3.86 and 3.88. This was also supported 
by favourable mean scores of 3.92 for willingness to share with others, and brotherly care (3.89). Importantly, the fact that respondents' mean scores of 3.67 to 3.89 reflected that managers were being authentic about their emotional support and interactions with staff, provided good news for South African hospitality managers. This indicated some form of existing Ubuntu style of management, which is related to Hofstede (1983)cultural relativity of the organisation or even House et al. (2004) collective culturallyendorsed leadership.

\section{Result of EFA}

EFA results for the Ubuntu measured items numbered 26 representing five factors. Only four factors as debated in the literature, were extracted. These factors included compassion, collectivism, survival, and respect and dignity. One of the five factors was excluded due to cross loading between other factors (Compassion, Respect and Dignity, and Collectivism). This result is interesting considering that group solidarity was replaced by collectivism according to the four-factor model described earlier in Figure 1. With the remaining four factors, two items were singled out for respect and dignity, and one item for the survival dimension. These items were removed because they had lowshared variance. The four retained dimensions of Ubuntu values accounted for 54.45 per cent total common variance explained. The same could be said for internal reliabilities where .88 represented compassion, .86 collectivism, .73 survival, and .76 respect and dignity. This suggested that all four dimensions exceeded the minimum recommended acceptable level of .70.

\section{DISCUSSION, CONCLUSION AND RECOMMENDATIONS}

This research is one of the rare initiative studies that utilised three different methods in a triangulation approach in order to explore the factorial validity of a new version of an Ubuntu style of management instrument. The author of this paper tied what has, to date, been conceptualised as five separate streams of Ubuntu philosophy research. The use of varied elements of Ubuntu by various studies has led to considerable confusion in the literature concerning African management and Ubuntu at the most general level of society. Defining Ubuntu in a manner that allows for its measurement has to date been limited to to a focus on four principles without taking into account the collectivist dimension as an integral part of Ubuntu. Theoretically, this paper make, albeit, a small contribution by providing a consolidation of the antecedents of Ubuntu elements and by incorporating collectivism dimension as part African culture and the Ubuntu notion which most research in cross-culture studies tended to overlook. Based on these antecedents of each Ubuntu element, item measures are developed. The proposed measurement scale for the Ubuntu concept has the potential to be generalised to other forms of business organisations which might be applicable and relevant to other African multicultural populations.

The practical contribution that this study makes, is that managers can use Ubuntu practical ideas drawn from both, the literature and the current empirical research findings to enhance team collectiveness, care towards others and support for organisational goals, even during difficult times. Building from these practical ideas and lessons, managers of tourism and hospitality organisations could facilitate better management of the experiences of frontline employees and foster the development of positive attitudes and improved team performance outcomes such as service quality. With regard to Ubuntu compassion, McGregor (1960) motivational theory seems to be aligned with this element in that it suggests managers' understanding of employees' feelings and the need for management styles that resonate with employee struggles. In explaining McGregor (1960) theory $\mathrm{Y}$, understanding managers are viewed as those that take a more positive view on people.

Following the leads of House et al. (2004), it is argued that organisational productivity requirements by managers such as assuring service quality excellence should consider the implications of Ubuntu in the context of South African service business and contribution to the generation of accepted African cultural dimensional theories of organisational decision-making (consensus) and collectivism could be extended to other parts of the sub-Sahara Africa region. Lessons to be learned by hospitality managers resulting from exploring the measured concepts of Ubuntu and organisational performance, highlighted that opportunities exist in the hospitality sector to begin looking at key elements of the Ubuntu concept as it can complement existing management styles. Empirical research further showed that top management should be in touch with the feelings and perceptions of frontline managers, and must ensure that the policies that are put in place lead to the desired work outcomes.

\section{LIMITATIONS}

This study is not without limitations. The author acknowledges that while this study makes contribution to the theory and practices that it may not be as easy as it sounds to implements Ubuntu in an organisation. One reason for this is based on the acknowledgement of the participants that 
Ubuntu may be perceived as a culture that support certain group of people. Some researchers noted that it may be difficult to implement an old ancient wisdom in a modern society. These kinds of statements were seen by other participants as developing stigma amongst those that want to practice Ubuntu in the workplace. These need to be taken into account whenever an attempt is made to apply Ubuntu in an organisation as not all people may embrace Ubuntu notion. After all, some managers of businesses may not be interested in collective-decision making and group consensus as it may delay decision making process.

\section{RECOMMENDATIONS FOR FURTHER RESEARCH}

Most research which were supported by the current findings highlight Ubuntu as a universal concept that does not discriminate against race, age, gender and strangers and is considered by Mangaliso (2001) as one of the African wisdom that promote the common good. However, it is rec- ommended that future research should consider conducting empirical research that would establish what people of different cultures believe Ubuntu is and what could be the impediments for applying Ubuntu management for people who have not grown up in an Ubuntu culture/environment or with no knowledge of Ubuntu. Such studies would enable a better understanding of Ubuntu application and identify ways that help isolate areas that impede the development of Ubuntu as an additional source of insight that could complement existing cultural dimensions theories. It is also recommended that a preliminary test of hypotheses concerning the relationship between management style and team performance based on the antecedents of Ubuntu elements developed in this study is conducted. Further research could make use of the emergent questionnaire items using a five-point Likert scale to test quantitatively, the reliabilityinternal consistency and internal and external validity of the measures.

\section{REFERENCES}

Archer, E., Herman, H., van Vuuren, J., \& Hugo, D. (2017). Introduction to Atlas ti: Basic operations, tips and tricks for coding. California, CA: Research Rescue.

Babakus, E., Yavas, U., Karatepe, O. M., \& Avci, T. (2003). The effect of management commitment to service quality on employees' affective and performance outcomes. Journal of the Academy of Marketing Science, 31(3), 272-286. doi: https://doi.org/10.1177/0092070303031003005

Basit, T. (2003). Manual or electronic? the role of coding in qualitative data analysis. Educational Research, 45(2), 143-154. doi:https://doi.org/10.1080/0013188032000133548

Battle, M. (1996). The ubuntu theology of Desmond Tutu. In, Archbishop tutu: Prophetic witness in South Africa. Cape Town, South Africa: Human \& Rousseau.

Brod, M., Tesler, L. E., \& Christensen, T. L. (2009). Qualitative research and content validity: Developing best practices based on science and experience. Quality of Life Research, 18(9), 12-63. doi:https://doi.org/10.1007/s11136-009-9540-9

Broodryk, J. (2005). Ubuntu management philosophy: Exporting ancient African wisdom into the global world. Randburg, South Africa: Knowres Publishing.

Browning, V. (2006). The relationship between HRM practices and service behaviour in South African service organizations. The International Journal of Human Resource Management, 17(7), 1321-1338. doi:https://doi.org/10.1080/ 09585190600756863

Brubaker, T. A. (2013). Servant leadership, Ubuntu, and leader effectiveness in Rwanda. Emerging Leadership Journeys, 6(1), 114-147.

Churchill Jr, G. A. (1979). A paradigm for developing better measures of marketing constructs. Journal of Marketing Research, 16(1), 64-73. doi:https://doi.org/10.2307/3150876

Corbin, J. M., \& Strauss, A. (1990). Grounded theory research: Procedures, canons, and evaluative criteria. Qualitative Sociology, 13(1), 3-21. doi:https://doi.org/10.1007/bf00988593

Cuyugan, A. B. S., Agus, G. E., Dasig Jr., D. D., Nidea, M. A., Claricia, E. E., Taduyo, M. A. B., \& Camacho, E. J. (2017). In aid of community policy and framework development: A sustainable integrated community advancement program. Journal of Advanced Research in Social Sciences and Humanities, 2(2), 87-95. doi:https://doi.org/10.26500/jarssh-02-2017 $-0202$

Eisenberger, R., Stinglhamber, F., Vandenberghe, C., Sucharski, I. L., \& Rhoades, L. (2002). Perceived supervisor support: Contributions to perceived organizational support and employee retention. Journal of Applied Psychology, 87(3), 565-573. doi:https://doi.org/10.1037/0021-9010.87.3.565 
Esterberg, K. G. (2002). Qualitative methods in social research. Boston, MA: McGraw-Hill.

Hair, J. F., Black, W. C., Babin, B. J., Anderson, R. E., Tatham, R. L., et al. (2006). Multivariate data analysis. Upper Saddle River, NJ: Pearson Prentice Hall.

Hasson, F., Keeney, S., \& McKenna, H. (2000). Research guidelines for the delphi survey technique. Journal of Advanced Nursing, 32(4), 1008-1015. doi:https://doi.org/10.1046/j.1365-2648.2000.t01-1-01567.x

Hinkin, T. R. (1995). A review of scale development practices in the study of organizations. Journal of Management, 21(5), 967-988. doi:https://doi.org/10.1177/014920639502100509

Hofstede, G. (1980). Motivation, leadership, and organization: Do American theories apply abroad? Organizational Dynamics, 9(1), 42-63. doi:https://doi.org/10.1016/0090-2616(80)90013-3

Hofstede, G. (1983). The cultural relativity of organizational practices and theories. Journal of International Business Studies, 14(2), 75-89. doi:https://doi.org/10.1057/palgrave.jibs.8490867

House, R. J., Hanges, P. J., Javidan, M., Dorfman, P. W., \& Gupta, V. (2004). Culture, leadership, and organizations: The Globe study of 62 societies. New York, NY: Sage Publications.

IBM Corporation. (2013). IBM SPSS statistics for windows. Retrieved from https : //ibm. co/3aVgvWU

Jackson, T. (2004). Management and change in Africa: A cross-cultural perspective. London, UK: Psychology Press.

Jones, J., \& Hunter, D. (1995). Qualitative research: Consensus methods for medical and health services research. Bmj, 311(7001), 376-380. doi:https://doi.org/10.1136/bmj.311.7001.376

Khoza, R. (1994). The need for an afrocentric approach to management. Cap Town, South Africa: Centre for Business Studies. Khoza, R. (2004). Let Africa lead. Sunninghill, South Africa: Ubuntu Pathways.

Kiefer, K. M., Harris-Kojetin, L., Brannon, D., Barry, T., Vasey, J., Lepore, M., et al. (2005). Measuring long-term care work: A guide to selected instruments to examine direct care worker experiences and outcomes (Technical report). Office of the Assistant Secretary for Policy, US Department of Labor, Washington, DC, WA.

Kim, W. G., Leong, J. K., \& Lee, Y.-K. (2005). Effect of service orientation on job satisfaction, organizational commitment, and intention of leaving in a casual dining chain restaurant. International Journal of Hospitality Management, 24(2), 171-193. doi:https://doi.org/10.1016/j.ijhm.2004.05.004

MacDonald, P., Kelly, S., \& Christen, S. (2019). A path model of workplace solidarity, satisfaction, burnout, and motivation. International Journal of Business Communication, 56(1), 31-49. doi:https://doi.org/10.1177/2329488414525467

Mangaliso, M. P. (2001). Building competitive advantage from Ubuntu: Management lessons from South Africa. Academy of Management Perspectives, 15(3), 23-33. doi:https://doi.org/10.5465/ame.2001.5229453

Mbigi, L. (1993). The spirit of African empowerment. People Dynamics, 11(3), 12-14.

Mbigi, L. (1997). Ubuntu: The African dream in management. Cape Town, South Africa: Knowledge Resources.

Mbigi, L. (2000). In search of the African business renaissance: An African cultural perspective. New York, NY: Knowledge Resources.

Mbigi, L., \& Maree, J. (1995). Ubuntu, the spirit of African transformation management. New York, NY: Knowledge Resources. McGregor, D. (1960). The human side of enterprise. New York, NY: McGraw-Hill Book Company.

Mertz, T. (2007). Towards an african moral theory. Journal of Political Philosophy, 15(5), 321-341. doi:https://doi.org/ 10.1111/j.1467-9760.2007.00280.x

Mgidlana, S. (1997). South Africa. Cape Town, South Africa: Pace Magazine.

Molose, T., Thomas, P., \& Goldman, G. (2019). A qualitative approach to developing measurement scales for the concept of ubuntu. Acta Commercii, 19(1), 10-20.

Naeem, M., \& Hameed, Z. (2018). 'negative work-family spillover: The relationship between perceived subordinates' negative workplace gossip and supervisor family satisfaction: The role of workhome segmentation preferences. Journal of Advances in Humanities and Social Sciences, 4(2), 104-117. doi:https://doi.org/10.20474/jahss-4.2.5

Newenham-Kahindi, A. (2009). The transfer of ubuntu and indaba business models abroad: A case of South African multinational banks and telecommunication services in Tanzania. International Journal of Cross Cultural Management, 9(1), 87-108. doi:https://doi.org/10.1177/1470595808101157

Nicolaides, A. (2010). Cultural diversity training programme development for hospitality and tourism industry enterprises. In International Research Symposium in Service Management, Port Louis, Mauritius. 
Nussbaum, B. (2003). Ubuntu: Reflections of a South African on our common humanity. Reflections: The Sol Journal, 4(4), 21-26. doi:https://doi.org/10.1162/152417303322004175

Onwuegbuzie, A. J., Dickinson, W. B., Leech, N. L., \& Zoran, A. G. (2009). A qualitative framework for collecting and analyzing data in focus group research. International Journal of Qualitative Methods, 8(3), 1-21. doi:https://doi.org/10.1177/ 160940690900800301

Petzer, D., \& Steyn, T. (2006). Customer retention: A theoretical perspective of service failure and service recovery in the hotel industry. Acta Commercii, 6(1), 162-172. doi:https://doi.org/10.4102/ac.v6i1.106

Qobo, M., \& Nyathi, N. (2016). Ubuntu, public policy ethics and tensions in South Africa's foreign policy. South African Journal of International Affairs, 23(4), 421-436. doi:https://doi.org/10.1080/10220461.2017.1298052

Sigger, D. S., Polak, B., \& Pennink, B. J. W. (2010). Ubuntu'or 'humanness' as a management concept. CDS Research Journal, 29(6), 1-46.

Strauss, C., Taylor, B. L., Gu, J., Kuyken, W., Baer, R., Jones, F., \& Cavanagh, K. (2016). What is compassion and how can we measure it? A review of definitions and measures. Clinical Psychology Review, 47, 15-27. doi:https://doi.org/ 10.1016/j.cpr.2016.05.004

Swanson, R. A., \& Holton, E. F. (2005). Research in organizations: Foundations and methods in inquiry. Istanbul, Turkey: Berrett-Koehler Publishers.

The National Department of Tourism. (2011). The national tourism service excellence strategy. Retrieved from https:// bit.1y/33wDkxS

Tutu, D. (2011). God has a dream: A vision of hope for our times. New York, NY: Random House.

Van Dun, D. H., Hicks, J. N., \& Wilderom, C. P. (2017). Values and behaviors of effective lean managers: Mixed-methods exploratory research. European Management Journal, 35(2), 174-186.

Westmoreland, M. W. (2008). Interruptions: Derrida and hospitality. Kritike: An Online Journal of Philosophy, 2(1), 1-10. doi:https://doi.org/10.3860/krit.v2i1.566

Woermann, M., \& Engelbrecht, S. (2019). The Ubuntu challenge to business: From stakeholders to relationholders. Journal of Business Ethics, 157(1), 27-44. doi:https://doi.org/10.1007/s10551-017-3680-6

Yazici, H. (2016). The art of opera in turkey within the scope of culture-art policies. International Journal of Humanities, Arts and Social Sciences, 2(5), 159-164. doi:https://doi.org/10.20469/ijhss.2.20001-5 


\section{APPENDIX 1}

TABLE 2. Reliability Items of the Ubuntu experience scale

\begin{tabular}{|c|c|c|c|c|}
\hline Ubuntu Style of Management variables $(N=211)$ & Mean & Std. Dev & $N$ & $\begin{array}{l}\text { Cronbach Alpha if Item } \\
\text { Deleted }\end{array}$ \\
\hline $\begin{array}{l}\text { S1.1 My manager is usually present (emotionally) to share my pain } \\
\text { during difficult times. }\end{array}$ & 3.67 & 1.176 & 211 & .925 \\
\hline $\begin{array}{l}\text { S1.2 My manager is usually available (physically) to suffer with me } \\
\text { during difficult times. }\end{array}$ & 3.39 & 1.200 & 211 & .925 \\
\hline $\begin{array}{l}\text { S1.3 My manager encourages me to remain polite even when I dis- } \\
\text { agree with what the guest says. }\end{array}$ & 4.19 & 0.794 & 211 & .927 \\
\hline $\begin{array}{l}\text { S1.4 My manager responds selflessly to free me from suffering when } \\
\text { I am under pressure (e.g., manager involvement during busy group } \\
\text { guest check-in). }\end{array}$ & 3.89 & 1.058 & 211 & .925 \\
\hline $\begin{array}{l}\text { S1.5 I feel happy when I see my manager notices that I have personal } \\
\text { problems that may potentially affect my work performance. }\end{array}$ & 3.78 & 0.962 & 211 & .925 \\
\hline $\begin{array}{l}\text { S1.6 I feel a genuine authenticity/realness/honesty about my man- } \\
\text { ager and this is demonstrated in his/her empathetic interactions } \\
\text { with me and guests alike. }\end{array}$ & 3.86 & 1.009 & 211 & .924 \\
\hline $\begin{array}{l}\text { S1.7 I believe each employee should be willing to share (the little) } \\
\text { they have with others as a way of brotherly care. }\end{array}$ & 3.92 & 0.999 & 211 & .926 \\
\hline $\begin{array}{l}\text { S1.8 It is common practice for employees to sacrifice their time for } \\
\text { the good of other team members. }\end{array}$ & 3.86 & 0.969 & 211 & .926 \\
\hline $\begin{array}{l}\text { S1.9 I feel that sharing my difficulties (grief) with other colleagues } \\
\text { makes me strong. }\end{array}$ & 3.49 & 1.152 & 211 & .928 \\
\hline $\begin{array}{l}\text { S1.10 My manager share his/her burden during hard times (e.g., } \\
\text { budget cuts, salary pay cuts, restructuring or change of top man- } \\
\text { agement) as part of a team. }\end{array}$ & 3.34 & 1.209 & 211 & .929 \\
\hline $\begin{array}{l}\text { S1.11 I feel that my manager treats me with utmost respect and dig- } \\
\text { nity. }\end{array}$ & 4.11 & 1.015 & 211 & .925 \\
\hline S1.12 My manager greets me whenever he/she sees me. & 4.32 & 0.873 & 211 & .926 \\
\hline S1.13 My manager expects me to respect his/her decisions. & 4.37 & 0.753 & 211 & .926 \\
\hline $\begin{array}{l}\text { S1.14 My manager treats each staff member as if he/she was a mem- } \\
\text { ber of a family. }\end{array}$ & 3.87 & 1.155 & 211 & .923 \\
\hline $\begin{array}{l}\text { S1.15 I have a genuine backing (support) of my co-workers, such } \\
\text { that they are willing to help me when I need it. }\end{array}$ & 3.89 & 0.944 & 211 & .925 \\
\hline $\begin{array}{l}\text { S1.16 I actively contribute to work goals that benefit a wider group } \\
\text { particularly, where they are worse-off than me. }\end{array}$ & 4.03 & 0.789 & 211 & .925 \\
\hline $\begin{array}{l}\text { S1.17 I generally do trust my co-workers in matters of landing or } \\
\text { extending a helping hand. }\end{array}$ & 3.88 & 0.875 & 211 & .925 \\
\hline $\begin{array}{l}\text { S1.18 I have to be alert or else someone is likely to take advantage } \\
\text { of me. }\end{array}$ & 3.51 & 1.114 & 211 & .932 \\
\hline $\begin{array}{l}\text { S1.19 I do helpful things that will benefit me and the colleagues I } \\
\text { know. }\end{array}$ & 4.10 & 0.899 & 211 & .928 \\
\hline $\begin{array}{l}\text { S1.20 When something unfortunate happens to me (e.g., loss of fam- } \\
\text { ily member), my co-workers get together to help me out. }\end{array}$ & 3.91 & 1.001 & 211 & .925 \\
\hline $\begin{array}{l}\text { S1.21 I see myself as part of a diverse work team rather than as in- } \\
\text { dividual from a different cultural background or nationality. }\end{array}$ & 4.16 & 0.880 & 211 & .925 \\
\hline $\begin{array}{l}\text { S1.22 I feel that all employees should stick together as a family no } \\
\text { matter what sacrifices are required. }\end{array}$ & 4.10 & 0.892 & 211 & .926 \\
\hline $\begin{array}{l}\text { S1.23 I feel it is my duty to take care of my co-workers, even if I have } \\
\text { to sacrifice what I want. }\end{array}$ & 3.93 & 0.926 & 211 & .925 \\
\hline $\begin{array}{l}\text { S1.24 Being a valuable team player is very important to me than my } \\
\text { personal identity. }\end{array}$ & 4.10 & 0.853 & 211 & .927 \\
\hline S1.25 The wellbeing of my co-workers is important to me. & 4.25 & 0.703 & 211 & .926 \\
\hline $\begin{array}{l}\text { S1.26 It is important to me that I respect the decisions (e.g., how to } \\
\text { serve the customer) made by my co-workers. }\end{array}$ & 4.16 & 0.776 & 211 & .926 \\
\hline
\end{tabular}

Reliability Statistics, Cronbach Alpha $=.931, N$ of Items $=26$ Valid cases $=211(99.5 \%)$, Excluded cases $=1(0.5 \%)$, Total $=212$ Scale: 1 (strongly disagree); 2 (disagree); 3 (Neutral); 4 (agree); 5 (Strongly agree) 